\title{
The effect of carbamazepine on biochemical bone profile in epileptic patients
}

\author{
Deena K. Al-Samman*, Faris A. Ahmed** \\ Department of Pharmacology, ${ }^{*}$ College of Pharmacy, ** Nineveh College of Medicine, \\ University of Mosul,
}

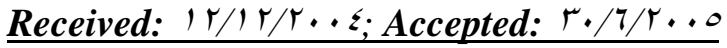

Objectives: To assess the biochemical bone profile in epileptic patients treated with carbamazepine monotherapy which include serum total calcium, phosphorus levels and alkaline phosphatase activity, and to investigate the relationship between these parameters with the age of the patients, daily dose of the drug and the duration of treatment.

Design: Case-control study.

Setting: The study was carried out in the Outpatient department of Ibin-Seena Hospital in Mosul, during the period from October $r \ldots r$ to March $r \ldots r$.

Participants: Seventy six epileptic patients on carbamazepine therapy and $V \tau$ apparently healthy subjects as a control group.

Main outcomes measures: Serum total calcium, phosphorus levels and alkaline phosphatase activity in epileptic patients treated with carbamazepine were compared with their corresponding values in the control group by using " $Z$ " test. The relationship between serum total calcium, phosphorus levels and alkaline phosphatase activity, with the age of the epileptic patients, daily dose or duration of treatment of carbamazepine, were also studied by using correlation coefficient.

Results: In epileptic patients treated with carbamazepine, serum total calcium was significantly lower $(\mathrm{P}<\bullet . \cdot)$ ) than the control group, while serum alkaline phosphatase activity was significantly higher $(\mathrm{P}<\bullet . \cdots)$ than the controls. At the same time, serum phosrus level was significantly higher $(\mathrm{P}<\cdot . \bullet)$ in those patients than the controls, although still within the normal range. No correlation was found between the ages of the epileptic patients treated with carbamazepine and their serum total calcium, phosphorus levels and alkaline phosphatase activity. Furthermore, no correlation was found between the daily dose of carbamazepine for those epileptic patients and their biochemical bone profile. However, significant correlation was noticed between the duration of treatment of carbamazepine and serum calcium level $(\mathrm{r}=-\cdot r \cdot r)$ and alkaline phosphatase activity $(\mathrm{r}=\cdot \mathrm{r})$.

Conclusion: This study encourage the use of carbamazepine for epilepsy as a sole therapy as no evidence of Anticonvulsant Osteomalacia . In addition, periodic biochemical checks for bone profile are indicated for epileptic patients.

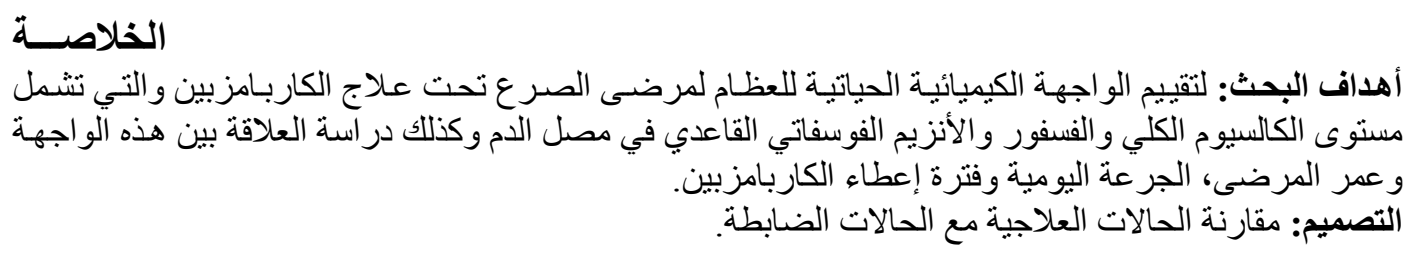




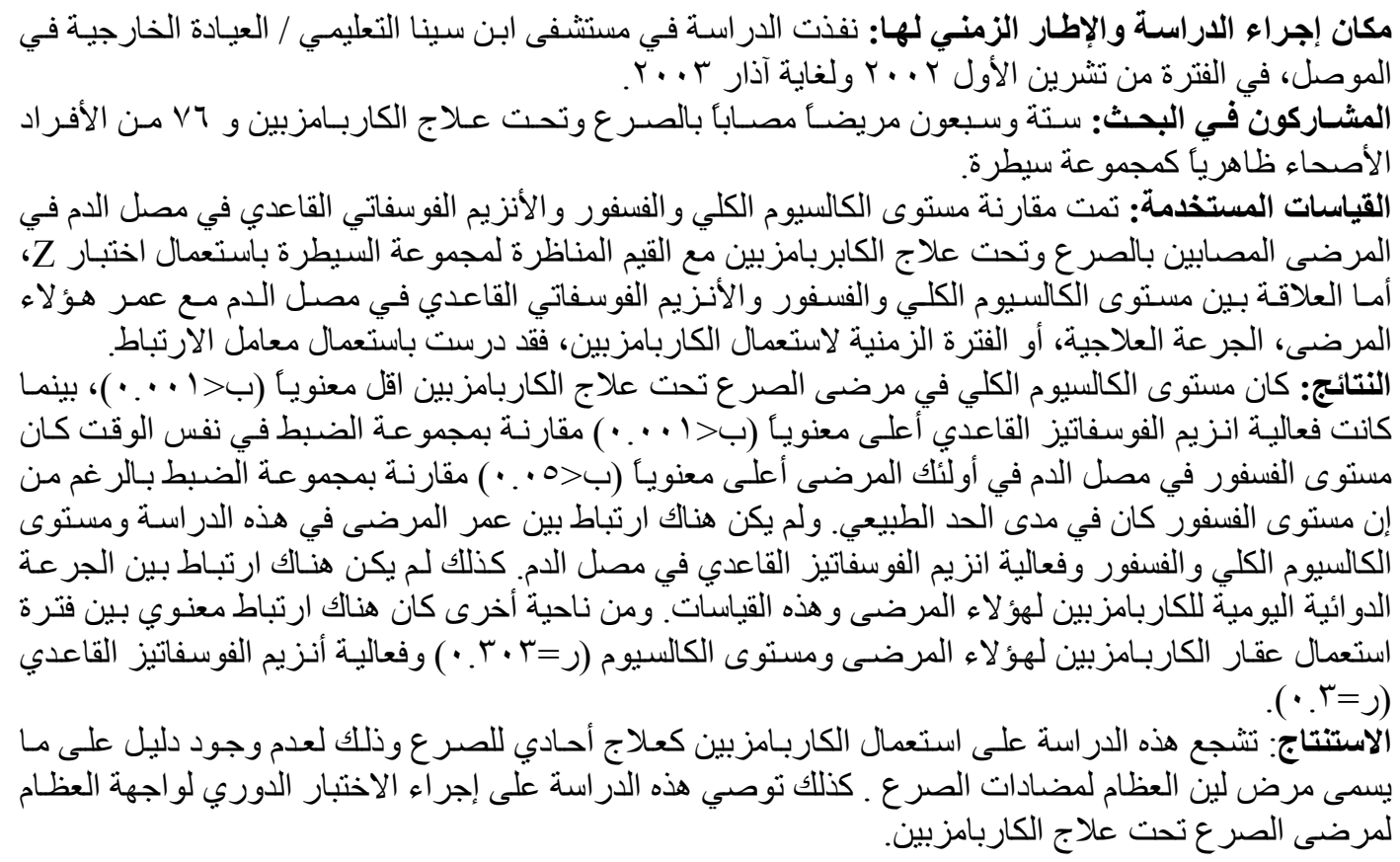

Introduction

$\mathrm{C}$ arbamazepine is the drug of choice for partial seizures and generalized tonic-clonic seizures ${ }^{(1)}$ and it is effective in the treatment of trigeminal neuralgia $^{(r)}$.

Adverse effects occur in approximately one-third of the treated patients with carbamazepine and are more frequent in patients on polytherapy ${ }^{(r)}$. Bone disease has been associated with anticonvulsant drugs for more than $r$. years $^{(\xi)}$. Furthermore, early investigators were mainly concerned about the potential of these drugs, mostly, phenytoin, primidone and phenobarbitone to induce bone disease ${ }^{(0)}$. However, in recent years, the focus have shifted to the question of whether the other anticonvulsant drugs like carbamazepine and valproic acid would affect bone and mineral metabolism ${ }^{(\urcorner)}$. As a result, the term "Anticonvulsant Osteomalacia" has been coined to characterize the constellation of anticonvulsant drug-induced mineral $\operatorname{disorders}^{(\mathrm{V})}$.

Previous studies showed that "Anticonvulsant Osteomalacia" was related to the dose and duration of therapy ${ }^{(\wedge)}$. Hahn et al. ${ }^{(9)}$ found that the larger daily doses of the received drug and the multiple drug regimens, produced more reduction in serum total calcium level, ro hydroxy- cholecalciferol, elevated alkaline phosphatase activity as well as severe derangements in mineral metabolism. Furthermore, incidence of these abnormalities increased with the duration of therapy ${ }^{(\cdot)}$. In addition to that, various antiepileptic drugs differed in their ability to produce disorder in mineral metabolism ${ }^{(')}$. However, the effect of carbamazepine on the biochemical bone profile was contraversal $^{\left({ }^{(r)}\right.}$. Tjellesen et al. ${ }^{\left({ }^{\top r}\right)}$ found that monotherapy with carbamazepine had no side effects on bone metabolism and the reduction in serum total calcium level and the elevation in alkaline phosphatase activity were related to the hepatic enzyme induction by carbamazepine, but Hoikka et al. ${ }^{\left(I^{\xi}\right)}$ found that epileptic outpatients received carbamazepine therapy had vitamin D deficiency and osteomalacia. This study was done to investigate the effect of long-term use of carbamazepine monotherapy in epileptic patients on serum calcium, phosphorus levels and alkaline phosphatase activity. Furthermore, the correlations of these biochemical parameters with sex, age of 
the patients, dialy dose and the duration of therapy were-studied.

\section{Patients And Methods}

The study was carried out in the Neurology Outpatient Department at IbnSeena Hospital in Mosul, from October r..r to March r..r. This study included $V \uparrow$ active ambulatory epileptic patients. They received carbamazepine monotherapy for at least 1 months. Patients taking any medication in addition to carbamazepine were excluded from this study. The selected patients comprised 0 . males and $Y \checkmark$ females, their ages ranged between 1 $\tau_{-} \leqslant V$ years (mean $\pm \mathrm{SD}$, $r \cdot .0 \pm 9 . \leqslant$ years) and $1 \tau_{-} \leqslant 0$ years (mean $\pm \mathrm{SD}, r, r_{ \pm} \uparrow . \wedge$ years) respectively. The duration of treatment was between $\cdot 0_{-} r$. years (mean $\pm \mathrm{SD}, \wedge . q_{ \pm}$.) years) with daily dose range between $r \ldots . l\} \ldots$ $\mathrm{mg} /$ day (mean $\pm \mathrm{SD}$, or $\varepsilon_{ \pm} 191 \mathrm{mg}$ /day). Radiological examination for $\mathrm{x}$-ray were taken for most of the patients of pelvis for any osteomalacic changes.

Control subjects were apparently healthy with any medication. This group comprised $V_{\tau}$ subjects, divided into \& males and ro females. Their ages matched with the patient group and ranged between

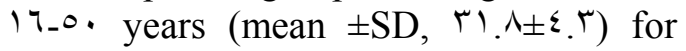
male and the ages ranged for females between $1 V_{-} \circ$. years (mean $\pm \mathrm{SD}$, $r 9.0 \pm 9.0)$

Blood samples were taken from each subject and analysed for serum total calcium, inorganic phosphorus, alkaline phosphatase activity and albumin. Serum calcium was measured by methylthymol blue as indicator ${ }^{\left({ }^{\circ}\right)}$. Phosphorus was measured by using phosphomolybdate reaction ${ }^{(1)}$. Alkaline phosphatase activity was estimated according to the method of kind and king $^{(')}$, while albumin was determined by bromocresol green ${ }^{(\wedge)}$. The kits for determination of calcium, phosphorus and alkaline phosphatase were obtained from bio Merieux (France), while albumin kit was obtained from Randox (UK).

Corrected calcium was used in this study, since any change in serum albumin would affect the measurement of calcium.
The corrected calcium was calculated by using the following equation ${ }^{(19)}$ : Corrected calcium $(\mathrm{mmol} / \mathrm{l})=$ measured calcium $+\cdot \cdot r(\varepsilon \cdot-$ albumin in $\mathrm{g} / \mathrm{l})$ Z-test was used to compare the difference between the treated patients with carbamazepine and the control group for serum total calcium, phosphorus and alkaline phosphatase activity ${ }^{\left(r^{\cdot}\right)}$. Correlation coefficient was used to determine the relationship between these parameters and age, daily dose and duration of therapy ${ }^{(r \cdot)}$.

\section{Results}

In the epileptic patients treated with carbamazepine, mean serum total calcium was significantly decreased $(\mathrm{P}<\bullet . \cdots)$ though did not reach hypocalcaemia, while serum alkaline phosphatase activity was significantly increased $(\mathrm{P}<\cdot \cdot \cdot)$ in comparison with the controls, as shown in Table 1. Furthermore, values of measured calcium were not significantly different from corrected calcium values in both the control group and carbamazepine treated patients.

Firgure 1. showed a significant negative correlation between the duration of taking carbamazepine in epileptic patients and the reduction in serum total calcium level $(\mathrm{P}<\cdot . \cdot)$. At the same time, no correlation was found between the duration of treatment and serum phosphorus level. However, a significant correlation between the duration of carbamazepine treatment and the activity of serum alkaline phosphatase $\left(\mathrm{P}<\bullet \cdot{ }^{\prime}\right)$. No significant correlation was found between the ages of carbamazepinetreated patients and serum total calcium, phosphorus levels and alkaline phosphatase activity. Furthermore, nonsignificant correlation was found between the daily dose of carbamazepine and serum total calcium, phosphorus

levels and alkaline phosphatase activity. None of the epileptic patients treated with carbamazepine had fracture. In addition, the radiological examinations were normal. 
Table (1): Biochemical bone profile in both the control group and carbamazepine treated epileptic patients represented by mean $\pm S D$.

\begin{tabular}{|c|c|c|c|}
\hline Parameters & Controls $(n=\vee\urcorner)$ & Patients $(n=\vee\urcorner)$ & P value \\
\hline Calcium $(\mathrm{mmol} / \mathrm{L})$ & T.r. $\pm \cdot .190$ & $\overline{r . r T \pm \cdot .1 \wedge \Lambda}$ & $\mathrm{P}<\bullet \cdots 1$ \\
\hline Phosphorus (mmol/L) & $1.17 \pm \cdot .1 \leq$ & 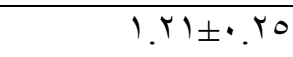 & $\mathrm{P}<\cdot .0$ \\
\hline Alkaline phosphatase $(\mathrm{u} / \mathrm{L})$ & $7 \leq . r \pm 17.7$ & $q r . r \cdot \pm r q . r \cdot$ & $\mathrm{P}<\cdot . \cdot 1$ \\
\hline Albumin $(\mathrm{g} / \mathrm{L})$ & $\sum 1 . V 0_{ \pm} r .71$ & $\varepsilon 1 . \varepsilon \gamma_{ \pm} \varepsilon . \varepsilon \wedge$ & $\mathrm{NS}$ \\
\hline
\end{tabular}
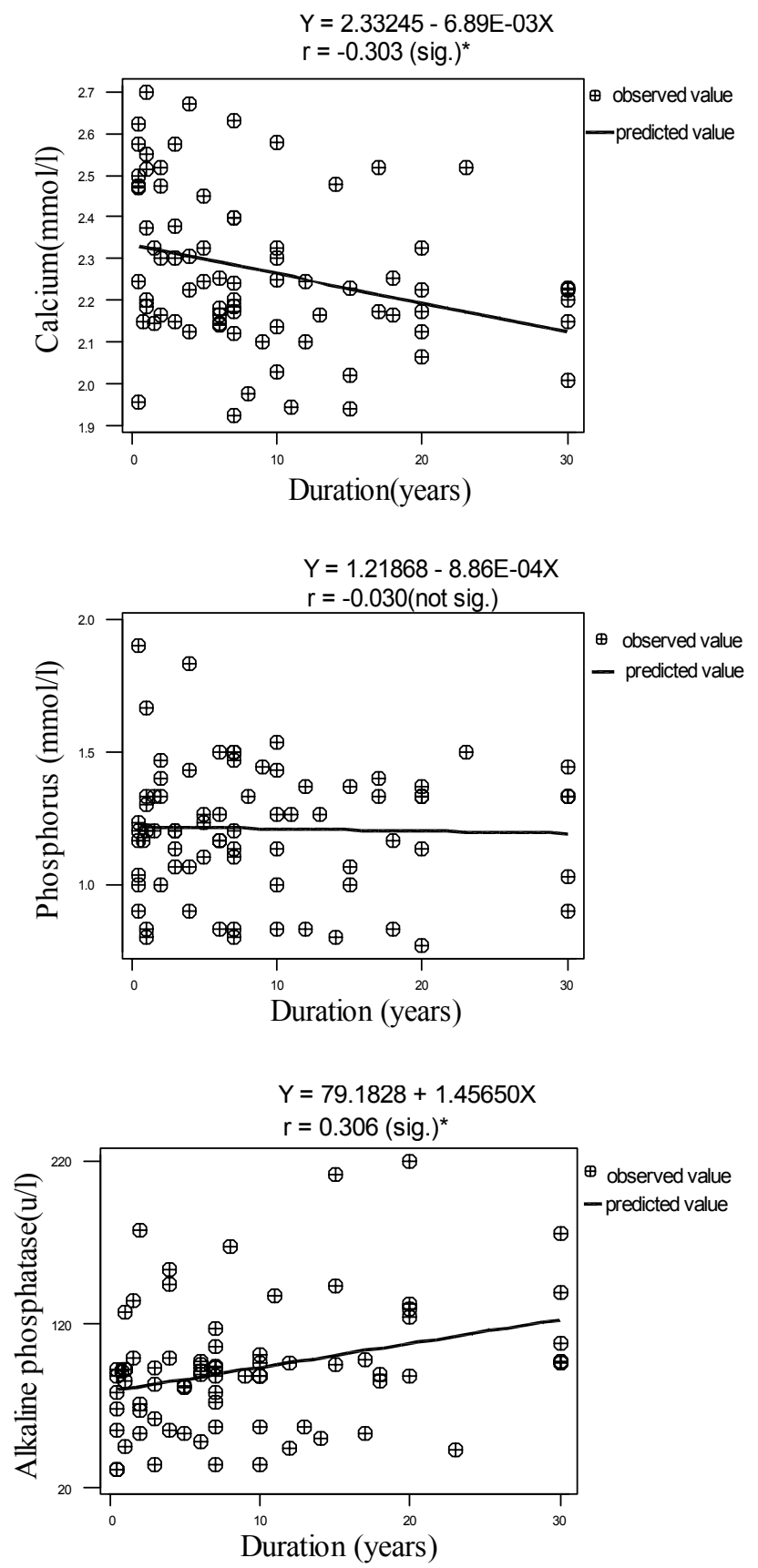

Figure ( '): The relationship between the duration of treatment of the carbamazepine in epileptic patients and the measurements of serum total calcium, phosphorus levels and alkaline phosphatase activity, ${ }^{*} \mathrm{P}<\cdot \cdot \cdot$ l. 


\section{Discussion}

In the present study, serum total calcium level was lower significantly, while serum alkaline phosphatase activity was higher significantly in the carbamazepine treated patients as compared with the control group. These results were in agreement with other studies $^{(r), r)}$. Furthermore, hypocalcaemia and elevated alkaline phosphatase activity were reported in epileptic patients treated with phenytoin, phenolbarbital and primidone ${ }^{(1,, r r)}$. However, Golden et al. ${ }^{\left({ }^{(r)}\right)}$ and Shah et al ${ }^{\left(\Upsilon_{\xi}\right)}$ found that no significance in serum total calcium level was noticed in carbamazepine-treated patients as compared with the control group.

The exact cause of the reduction in serum total calcium level is still unclear. Pack $^{\left(\Upsilon_{0}\right)}$ found that chronic therapy with phenytoin and / or phenobarbital resulted in a significant reduction in serum level of ro - hydroxycholecalciferol. Therefore, reduced availability of $r{ }^{\circ}$ hydroxycholecalciferol would cause a deficiency of the active metabolites $1, r^{\circ}$-dihydroxycholecalciferol and $r \varepsilon$, ro- dihydroxycholecalciferol, which play an important role in the bone formation and in the maintenance of normal calcium homeostasis, leading to hypocalcaemia and osteomalacia ${ }^{(\mathrm{V})}$. In the present study, the alkaline phosphatase activity was significantly higher in the carbamazepine-treated patients than the control. Richens and Rowe $^{(11)}$ found that an increase of both liver and bone isoenzymes accounted for the higher total serum activity; however, the hepatic fraction was predominant. These observations were confirmed by Gough et al. ${ }^{(\Upsilon)}$ who found that serum alkaline phosphatase activity rose in phenytoin, phenobarbital and carbamazepine but not in case of sodium valproate therapy. On the other hand, Okesina et al. ${ }^{(\Upsilon Y)}$ noticed that the elevated alkaline phosphatase activity in patients receiving carbamazepine monotherapy was mainly from bone rather than from liver origin. In this study, serum phosphorus level was significantly higher in the carbamazepine-treated patients as compared with the control group, but still within the normal reference range. Taghi et al ${ }^{(\uparrow \wedge}$ reported that phosphorus level was unaffected by treatment with phenytoin, phenobarbital and carbamazepine whether mono or combined therapy. However, Shriraam et al. ${ }^{(\Upsilon 9)}$ found that phosphorus level was reduced during treatment with phenytoin, phenobarbital and carbamazepine together as combined therapy. These results showed a significant correlation between the duration of treatment with carbamazepine and serum total calcium level and alkaline phsophatase activity. Tolman et al. ${ }^{(\Gamma \cdot)}$ found that a significant correlation between those parameters and long term therapy with phenytoin and / or phenobarbital. However, Mosekilde and Melsen $^{(r)}$ demonstrated that no significant correlation between the duration of treatment with phenytoin, phenobarbital, primidone and carbamazepine as monotherapy or as polytherapy in various combination, and the changes in those biochemical bone profile.

This study showed that no correlatin was found between the ages of both the control group and carbamazepinetreated patients and serum total calcium, phosphorus levels and alkaline phosphatase activity. These results might be related to the middle age of these groups (mean $\pm \mathrm{SD}, r \cdot .0_{ \pm} 9 .{ }^{\circ}$ years), since age plays an important role in serum level of vitamin $D^{(r r)}$.

No significant correlatin was found, in this study, between the total daily dose of carbamazepine and the biochemical bone profile. These results were probably due to the moderate doses of carbamazepine. Other cause might be related to the use of carbamazepine as a sole antiepileptic drug. Christiansen et al. ${ }^{(\top r)}$ did not find a significant corr- 
elation between the dose of phenytoin monotherapy and serum total calcium, phosphorus levels and alkaline phsophatase activity. On the other hand, "Anticonvulsant Osteomalacia" was related to the dose of phenytoin, phenobarbital, primidone and carbamazepine as polytherapy in various combinations $^{(1,+r \cdot)}$.

Several studies showed a radiological evidence of osteomalacia in epileptic patients being treated with phenytoin, phenobarbital and carbamazepine in various combinations ${ }^{(r \cdot, r)}$. However, in the present study, none of these patients had fracture and the radiological examination were normal in addition the biochemical findings were not compatible with the biochemical changes of "Anticonvulsant Osteomalacia" .

In conclusion, this study encourage the use of carbamazepine as a sole antiepileptic drug as no evidence of osteomalacia was reported. In addition, periodic biochemical checks for osteomalacia and radiograph for the bone are indicated. Moreover, advising the patients for the importance of dairy in take, physical activity as well as sunlight exposure is necessary to prevent "Anticonvulsant Osteomalacia".

\section{References}

1. Feely M. Drug treatment in

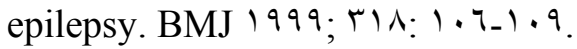

$r$. Tomson U, Tybring G, Bertilsson L, Ekhom K and Rane A. Carbamazepine therapy in trigeminal neuralgia. Arch Neurol 19^.;rv: $r 99 \_v \cdot r$.

r. Rimmer EM and Richens A. Clinical pharmacology and medical treatment. In: A Textbook of Epilepsy. Laidlaw J, Richens A and Oxely J (Eds). Churchill living stone, London

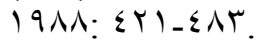

$\varepsilon$. Kruse R. Osteopathien bei antiepileptischer Langzeitherapic. Mschr Kinderhilk 197^; 117 : rVA_rA.

-. Dent CE, Richens A, Rowe DJF and Stamp TCB. Osteomalacia with longterm anticonvulsant therapy in epilepsy. BMJ $19 \vee \cdot ;$ ₹: १९_V .

ๆ. Wettengl GR. Tutlewski B, Stabrey A, Rauch F, Herkenrath $\mathrm{P}$ and Schoenau E. Analysis of the musculoskeletal system in children and adolescents receiving anticonvulsant monotherapy with valproic acid or carbamazepine. Pediatr $Y . .1$; 1. $1(7): 1.0$.

$\vee$. Hahn TJ. Drug-induced disorders of vitamin $\mathrm{D}$ and mineral metabolism. Clin Endocrinol Metabol $\left.191 \cdot ; 9(1): 1 \cdot v_{-}\right) \cdot 0$.

$\wedge$. Kruse K. pathogenesis of anticonvulsant drug-induced alterations of calcium metabolism. Eur $\mathrm{J}$ Pediatr 19Ar; IrA: r. r-r.o.

१. Hahn TJ, Hendin BA, Scharp CR and Haddad JG. Effect of chronic anticonvulsant therapy on serum ro $(\mathrm{OH}) \mathrm{D}$ levels in adults. $\mathrm{N}$ Engl $\mathrm{J}$ Med १९Vr; YAv: 9..-9.r.

1. Lifshitz $F$ and Maclaren NK. Vitamin D dependent rickets in institutionalized, mentally retarded children ceceiving long-term anticonvulsant therapy. Pediatr 19vr; $N r(\varepsilon)$ : $T / r_{-}$

11 Richens A and Rowe DJF. Disturbance of calcium metabolism by anticonvulsant drugs. BMJ $19 \vee \cdot ; \varepsilon$ : VT_V .

Ir.Hoikka V, Savolainen K, Alhava EM, Sivenius J, Karjalainen $\mathrm{P}$ and Repo A. Osteomalacia in institutionalized epileptic patients on longterm anticonvulsant therapy. Acta Neurol Scand 1911; Tะ: Mrr-Irl. 1 r.Tjellesen L, Nilas L and Christiansen C. Does carbamazepine cause disturbance in calcium metabolism in epileptic patients Acta Neurol Scand 19人r; т人: 1r-19.

I \&. Hoikk V, Alhava EM, Karjalainen $\mathrm{P}$, Keranen $\mathrm{T}$, Savolainen $\mathrm{K}$ and Korhonen R. Carbamazepine and bone mineral metabolism. Acta Neurol Scand 191ะ; 79: VV-A. 10. Robertson $G$ and Peacock M. New techniques for separation and measurement of calcium fractions of 
normal human serum. Clin ChemActa 197人; r.: r10.

17. Taussky HH and Shorr E. A micro colorimetric method for the determination of inorganic phosphorus. J Biol Chem 190r; r. Y: $7 \vee 0$.

IV. Kind PRN and King EJ. Estimation of plasma phosphatase by determination of hydrolysed phenol with amino-antipyrine. J Clin Pathol $190 \xi$; V: MYT_KY T. 1^.Wooton IDP. Proteins. In: Microanylasis in Medical Biochemistry. ${ }^{\circ}$ th ed., Churchil Livingstone, London, 19v ; 109_171.

19. Vanstapel FJ and Lissens WD. Free ionized calcium a critical survey. Ann Clin Biochem 191ะ; r): rrq_rol. $r$. Jones D. Pharmaceutical statistics. $\wedge^{\text {th }}$ ed. Pharmaceutical press, London, r... r.

r). Filardi S, Guerreiro CAM, Magnae and Neto JFM. Bone mineral density, vitamin $\mathrm{D}$ and anticonvulsant therapy. Arq Neuropsiquiatr r...; ON: 1..r-1..9.

rr. Shah QA, Jamil AA, Gupta VP, Shah AH and Kabiraj MM. Effect of antiepileptic drugs on biochemical levels in epileptic children $r \ldots r$; JST $r(1): r 0_{-} \varepsilon$ ). $r r$. Golden K, Taner E and Fatos. Effect of antiepileptic drugs on bone mineral density in children. Clin Pediatr 1999; $r \wedge(r): 9 r-9 \wedge$. $r \varepsilon$. Shah QA, Jamil AA, Gupta VP, Shah AH and Kabiraj MM. Antiepileptic drugs and body electrolytes in childhood epilepsy. JST

$$
\text { r..r; r (1): }\left\{r_{-} \circ \cdot\right.
$$

ro. Pack AM. The association between antiepileptic drugs and bone disease. Epilepsy Currents $r \ldots r ; r(r): 91-90$. $r 7$.Gough H, Goggin T, Bissessar A, Baker $\mathrm{M}$, Crowley $\mathrm{M}$ and Callaghan $\mathrm{N}$. a comparison study of the relative influence of different anticonvulsant drugs, UV exposure and diet on vitamin $\mathrm{D}$ and calcium metabolism in outpatients with epilepsy. Q.J. Med 1914; rq(YT.): OT9_OVV.
rv.Okesina AB, Donaldson D and Lasceles PT. Isoenzymes of alkaline phosphatase in epileptic patients receiving carbamazepine monotherapy. J Clin Pathol 1991; $\leqslant$ : $\leqslant \wedge \cdot-\varepsilon \wedge r$ r^. Taghi G, Jamshidi HR, Pharm D and Chorbani A. Anticonvulsant therapy-induced alteration in calcium homeostasis. MJIRI 1991; 0.(ץ, $\varepsilon)$ : IrO- ITV.

rq. Shriraam M, Bhansali A and Velayutham. Vitamin D deficiency masquerading as pseudohypoparathyroidism. JAPI Y.. T; 01: T19. Tr. $r \cdot$ Tolman KG, Jubiz W, Sannella JJ, Madsen JA, Belsey RE, Goldsmith RS and Freston JW. Osteomalacia associated with anticonvulsant drug therapy in mentally retarded children.

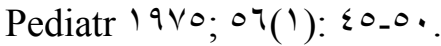
r. Mosekilde L and Melsen. Anticonvulsant osteomalacia determined by quantitative analysis of bone changes. Acta Med Scand 19v7; 199:r $49-400$. rr. Romagnoli E, Garavella P, Scarnecchia L, Martinez $\mathrm{P}$ and Minisola S. hypovitaminosis D in an Italian population of healthy subjects and hospitalized patients. BMJ 199^; N): ITr-ITV. rr. Christianson C, Rodbro P and Nielsen T. Tatrogenic osteomalacia in'epileptic children. Acta pediatr Scand 19v0; $7 \leqslant$ : r 19-r T . rะ. Goraya JS, Gupta PN, Gupta RK, Bahadur $\mathrm{R}$ and Parmer UR. Anticonvulsant induced osteomalacia. Indian Pediatr r...; rV: rro-rrA. 
